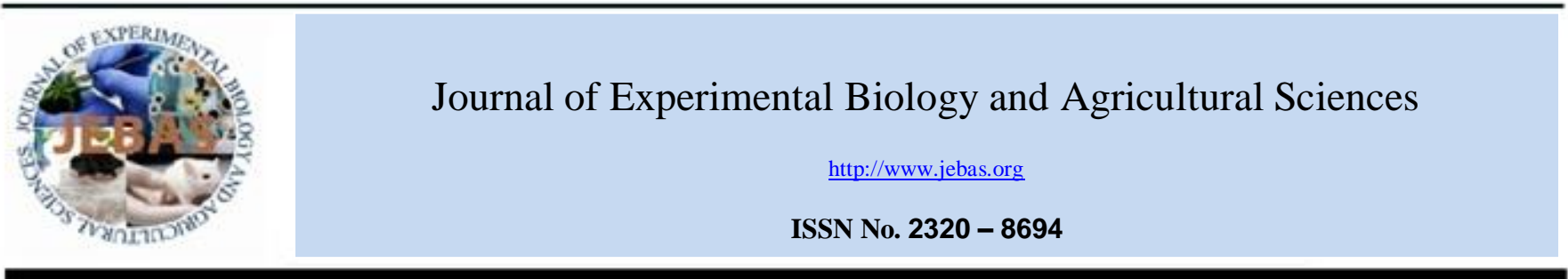

\title{
EFFICACY OF SILVER NANOPARTICLES SYNTHESIZED ON Commiphora gileadensis (BALSAM) EXTRACT AGAINST INFECTIOUS BACTERIA
}

\section{Bassam Oudh Al johny}

Department of Biological Science, Faculty of Science, King Abdulaziz University, PO Box 80203, Jeddah 21589, Kingdom of Saudi Arabia.

Received - April 10, 2019; Revision - May 21, 2019; Accepted - June 09, 2019

Available Online - June 10, 2019

DOI: http://dx.doi.org/10.18006/2019.7(3).301.307

\section{KEYWORDS \\ Commiphora gileadensis \\ Silver nanoparticles \\ E.coli \\ Multi-drug resistant \\ Staphylococcus aureus (MRSA)}

\begin{abstract}
Compare to the other metal ion, silver nanoparticles has wide application in the field of microbiology and pharmacology drug. The aim of present study was to synthesize cheap and eco-friendly silver nanoparticles on Commiphora gileadensis extract and evaluate its antimicrobial properties against selected bacterial strains. Aqueous extract of $C$. gileadensis was used for the synthesis of silver nanoparticles. These synthesized nanoparticles were characterized by using UV spectrophotometer, scanning electron microscope (SEM) and EDX. The characterization of AgNPs was carried out by uvvis spectrum at $\lambda \max =435 \mathrm{~nm}$ and the peak was correlated to the plasmonic nature of the particles as reported by number of earlier reports. In addition, EDX spectrum has been showed four peaks corresponding to the silver, zinc, carbon and oxygen. The results of present study indicated that the plant extract has very important role in the synthesis of AgNPs. Antibacterial activity of nanoparticles was evaluated using CFU method against E.coli O157:H7 and Methicillin-resistant Staphylococcus aureus (MRSA). Synthesized nanoparticles exhibit significant antibacterial activity against the infectious bacteria.
\end{abstract}

* Corresponding author

E-mail: boaljohny @kau.edu.sa (Bassam Oudh Al johny)

Peer review under responsibility of Journal of Experimental Biology and Agricultural Sciences.

Production and Hosting by Horizon Publisher India [HPI] (http://www.horizonpublisherindia.in/).

All rights reserved.
All the articles published by Journal of Experimental Biology and Agricultural Sciences are licensed under a Creative Commons Attribution-NonCommercial 4.0 International License Based on a work at www.jebas.org.

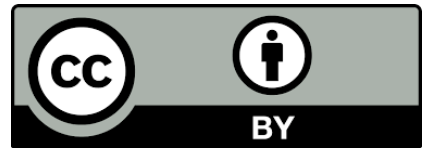




\section{Introduction}

Plant extracts are very important and many of them possess excellent biological properties (Abdul-Ghani \& Amin, 1997; Adebayo et al., 2014; Shaheen et al., 2017). Commiphora gileadensis (syn. C. opobalsamum) is very common aromatic shrub and the Red sea area is known as its native land, which encompasses the territory of Saudi Arabia, Ethiopia, Oman, Yemen and some other countries of this region (Wineman et al., 2015). C. gileadensis was first discovered by Carl Linnaeus from Yemen and identified as "Balm of Gilead" (Amiel et al., 2012). It is also known as balsam and find very useful for perfume industry (Miller et al., 1988). All parts of the balsam such as bark, wood, seeds, extract (Al-sieni, 2013) and plant Sap (Iluz et al., 2010) are frequently used in pharmaceutical industries. Oil containing balsam sap was considered of prime an incentive in getting ready medicinal balms (Iluz et al., 2010). According to Iluz et al. (2010), sap of balsam has capacity to cure cerebral pains. Crude methanolic extract of $C$. gileadensis showed significant antibacterial activity against E. coli, and Bacillus cereus, with a minimum inhibitory concentration of $62.5 \mu \mathrm{g} / \mathrm{ml}$ (Al-sieni., 2013).

Medicinal properties of this plant are well known and because of this it became active ingredient of many therapeutic drugs. For instance, dried bark has been placed on wounds as a germicide, while a tincture of ground balsam bark is utilized to treat various skin sicknesses such as aggravations and dermatitis (Mittal et al., 2013). Researcher also reported hypotensive impact of $C$. gileadensis; oral administration of plant extract initiate muscarinic cholinergic receptors of the mind, which initiate hypotensive impact which is at par the effect given by atropine sulfate (1-4 $\mathrm{mg} / \mathrm{kg}$ ). In addition, the leaves of balsam plant were utilized by Arab populaces as pain relieving, purgative and diuretic operators (Abdul-Ghani \& Amin, 1997). Another investigation on rats revealed positive impact of plant extricate in the treatment of tentatively delivered stomach ulcers.

As stated earlier that extract of C. gileadensis has been used effectively against the bacterial growth but its high dosage was recommended. Therefore, it is utmost important to explore the alternate ways of using this plant extract for the bacterial growth inhibition. One of the effective way of using plant extracts is to utilize it for the synthesis of metal nanoparticles (Nps). In fact, metal Nps have been found highly significant in many studies related to various scientific fields (Ahmed et al., 2016a; Ali et al., 2017a; Ali et al., 2017b). Nowadays, plant extracts based Nps synthesis is one of the emerging field of nanotechnology. Various studies have reported the use of Silver nanoparticles (AgNps) in medicine, consumer products, food-technology and in other industrial products because of their exclusive chemical, catalytic, sensing, wound healing and physical properties (Ahmed et al., 2016a; Kamal et al., 2017; Haider et al., 2018; Ali et al., 2018a; Ali et al., 2018b). The AgNps have attained lots of attention because of their physical and chemical properties i.e., conductivity, catalytic activity, stability, being non-reactive \& non-toxic and eco-friendly. Along with above mentioned properties, AgNps have extremely exalted antifungal, antiinflammatory, antiviral and antibacterial activities and can be used in field of medicine for treating and diagnosis many chronic and acute diseases (Mittal et al., 2013; Bello et al., 2017b; Borros et al., 2018; Singh et al., 2018). The AgNps have great application in biomedical leading to the production of antiseptic sprays, dressing's wounds fabrics as well as antiseptic topical creams. Antibacterial and antifungal properties of the AgNps have also been reported, which demonstrated that AgNps disrupt cell membrane of the unicellular microbes leading to plasmolysis and hence kill the microbes (Khan et al., 2015; Wajid Ullah et al., 2016). In addition, disruption of the cell membrane results deterioration of membrane bound enzymes and cause deactivation of the enzymes, which cause death of microorganisms (Kamal et al., 2016; Bello et al., 2017b). The efficacy of the AgNps is greatly dependent of $\mathrm{pH}$, size, ionic strength and capping agent of nanoparticles (Ahmed et al., 2016b). The synthesis of AgNps attained greater attention of the researchers because of their broader applications range and utilities in medicine and diagnosis against variety of cancers (Kuppusamy et al., 2016). Present study has been undertaken to assess the antimicrobial properties of AgNps synthesized on C. gileadensis extract. Moreover, these AgNps were synthesized against E.coli O157:H7 and a common antibacterial drug-resistant Staphylococcus aureus (MRSA).

\section{Materials and Methods}

\subsection{Culturing of Pathogenic Bacteria}

E.coli O157:H7 and multi drug-resistant Staphylococcus aureus MRSA which used as model bacteria were provided by King Fahad Center, King Abdulaziz University, Jeddah, Saudi Arabia. These microorganisms were used for the evaluation of bactericidal activity of synthesized nanoparticles. Nutrient agar (SigmaAldrich-70148) contains $5 \mathrm{~g} / \mathrm{L}$ peptones, $2 \mathrm{~g} / \mathrm{L}$ yeast extract, $1 \mathrm{~g} / \mathrm{L}$ meat extract, $2 \mathrm{~g} / \mathrm{L}$ sodium chloride and $15 \mathrm{~g} / \mathrm{L}$ agar in deionized water was used for culturing these pathogenic bacteria. Media was prepared, autoclaved and pours into plates. Bacterial cells were transferred after solidification of media to culture plates.

\subsection{Antibacterial Assessment}

Colony forming unit (CFU) was used for the enumeration of bactericidal activity of silver nanoparticles synthesized using balsam plant extract. $100 \mu 1$ of E.coli O157:H7 and multi-drugresistant S. aureus (MRSA) were added to $10 \mathrm{ml}$ of tube 
containing nutrient broth medium along with silver nanoparticles . These tubes were incubated for 24 hours at $35^{\circ} \mathrm{C}$. The samples were serially diluted and then spreaded onto nutrient agar containing plates. Nutrient Agar plates were incubated for 24 hours in order to check colony formation. Colony counter was used in order to count the bacterial colonies. Each treatment was repeated thrice.

\subsection{Balsam extraction}

A highly acclaimed method of obtaining the plant extract was used for this study. First, a whole plant of balsam was obtained from Baddar, Madinah region, Saudi Arabia. Plant material cut into small pieces and transfer to mortar containing liquid nitrogen. These pieces were crushed into fine pieces using mortar and then incubate on magnetic stirrer for 48 hours. Then filtered using filter paper concentrated and dried. This whole process was performed over a period of one week.

\subsection{Biosynthesis of AgNPs}

Aqueous extract of balsam was treated with a solution of AgNO3. The treatment was performed in such a way that a solution of $1 \mathrm{Mm}$ of $\mathrm{AgNO} 3$ in final concentration was made. The mixture was stirred on a magnetic stirrer at $60{ }^{\circ} \mathrm{C}$. Next, the synthesis AgNPs was indicated by color change (brown) of the solution. After two days, the solution was centrifuged and mixture was collected after discarding the supernatant. The collected AgNPs were washed with distilled water and air-dried for characterization and further studies.

\subsection{Characterization of AgNPs}

Generally, the characterization of NPs required determining the size, shape, surface area and dispersity because its properties are dependent on these features. Formation of AgNPs was confirmed by Ultraviolet-visible spectral analysis (UV-vis) spectroscopy. The absorbance spectra were recorded using a UV-Vis spectrophotometer at a wavelength range of 300-700 nm. Fourier Transform Infrared Spectroscopy (FTIR) was performed on FTIR Spectrometer to detect the possible functional groups in biomolecules present in the plant extract.
The surface morphology and size of the AgNPs were analyzed by employing a Scanning electron microscope (SEM) and energy dispersive X-ray spectroscopy (EDX). The particle size distribution and surface charge of AgNPs were determined using particle size analyzer (Zetasizernano ZS) at $25^{\circ} \mathrm{C}$ with $90^{\circ}$ detection angle.

\section{Results and Discussion}

\subsection{Antibacterial study}

Various properties of the AgNps such as cryogenic super conducting materials, composite fibers, food industry, cosmetic products and in electronic gadgets have been well reported by various researcher's. In present study, the plant extract assisted AgNps have been used against the growth of two selected bacterial strains. Result of present study revealed that synthesized AgNps have significant antibacterial activities and inhibiting the bacterial growth which is a major concern. Growth characteristics of E.coli $\mathrm{O} 157: \mathrm{H} 7$ and MRSA are shown in figure $1 \&$ table 1.

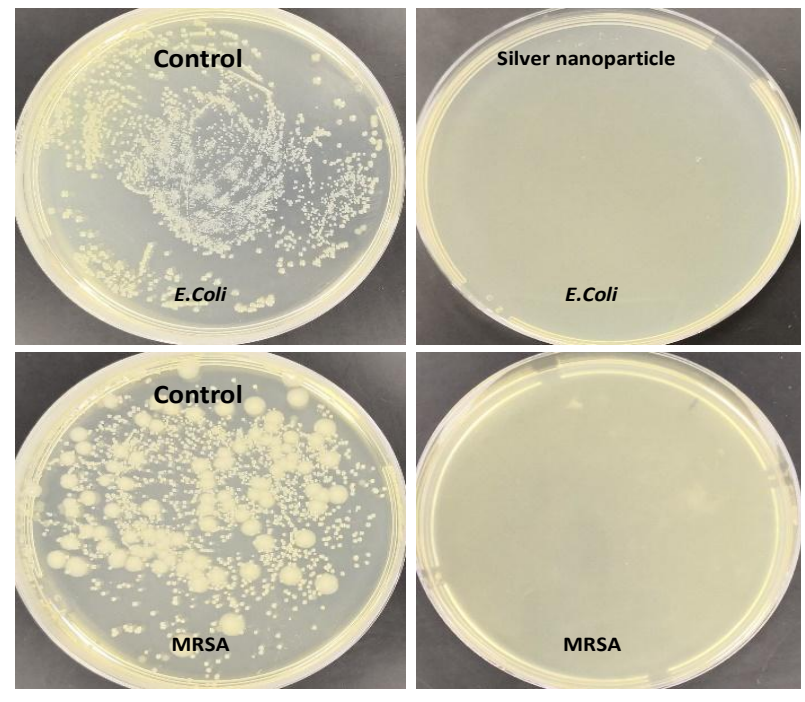

Figure 1 Growth of E. coliO157:H7 and Methiciallin-resistant Staphylococcus aureus (MRSA) on Nutrient, plate agar-showing inhibition in the presence of AgNPs

Table 1 Effectiveness of the AgNps against bacterial strains

\begin{tabular}{|lllll|}
\hline Treatments & Incubation Periods & & Reduction (\%) \\
& $12 \mathrm{Hrs}(\mathrm{Cfu} / \mathrm{ml})$ & $24 \mathrm{Hrs}(\mathrm{Cfu} / \mathrm{ml})$ & $12 \mathrm{Hrs}(\mathrm{Cfu} / \mathrm{ml})$ & $24 \mathrm{Hrs}(\mathrm{Cfu} / \mathrm{ml})$ \\
\hline Control $($ E.coli $\mathrm{O} 157: \mathrm{H} 7)$ & $76 \times 10^{6}$ & $102 \times 10^{6}$ & 0 & 0 \\
\hline E.coli $\mathrm{O} 157: \mathrm{H} 7+\mathrm{Ag} \mathrm{Nps}$ & $0 \times 10^{6}$ & $0 \times 10^{6}$ & 100 & 0 \\
\hline MRSA (Control) & $86 \times 10^{6}$ & $109 \times 10^{6}$ & 0 & 100 \\
\hline MRSA + Ag Nps & $0 \times 10^{6}$ & $0 \times 10^{6}$ & 100 & 00 \\
\hline
\end{tabular}

Journal of Experimental Biology and Agricultural Sciences http://www.jebas.org 
Results of study revealed that control (without AgNps nanoparticles) did not have any inhibition activity after 24 hours, while silver nanoparticles showed highest inhibition in E.coli $\mathrm{O} 157: \mathrm{H} 7$ and MRSA multiplication. This enhanced activity may be attributed to the silver nanoparticles. As E.coli is gram-negative bacteria that has a thin peptidoglycan layer and has complex cell wall containing two cell membrane (Kamal et al., 2016). The cell membrane of this bacteria is negatively charged, which may interact with the positively charged silver nanoparticle. This interaction alters cell membrane properties by forming pits and blocking the intake of nutrients to the cell subsequently AgNPs penetrating inside bacterial cell, thereby causes DNA damage (Khan et al., 2015). Other than this mechanism, these nanocomposite can also produce highly reactive species when heavy metals react with proteins which leads to the inactivation of protiens, i.e. hydrogen peroxide, superoxide's or hydrogen radicals. In addition, toxicity studies of AgNPs was observed against Gram-positive Staphylococcus aureus ATCC 35696 showed silver ions can interact with the thiol groups in proteins and inactivate them as well DNA molecules become condensed by losing its replication ability (Sondi \& Salopek-Sondi, 2004).

\subsection{UV-visible spectroscopy analysis}

Figure 2 shows UV-vis spectrum of the synthesized silver nano particles. The spectrum was obtained after $48 \mathrm{~h}$ of mixing AgNO3 aqueous solution and balsam plant extract. The nearly colorless solution turned from faint light to yellowish and finally in brown color due to excitation of surface plasmonic nature in AgNps (Figure 3), which indicated the formation of the nanoparticles in the solution (Pourmortazavi et al., 2015).

In fact, strong absorbance occurred between the shapes of the surface plasmonic resonances (SPR) and wavelength, which related to the particle size and relative dimensions, consequently increasing in particle size makes the SPR peak move to longer wavelength. This observation was in line with other reports in the literature (Sondi \& Salopek-Sondi, 2004). A single broad peak at $\lambda \max =435 \mathrm{~nm}$ was observed in a UV-vis spectrum. The peak was correlated to the plasmonic nature of the particles as reported by earlier researchers (Bello et al., 2017a). It has been reported by Bello et al. (2017a) that the peak positions in the UV-vis spectrum of smaller particles $(20 \mathrm{~nm}$ or below size) can be observed in the range of $400-420 \mathrm{~nm}$. The existence of peak at $435 \mathrm{~nm}$ in this study reveals that the nanoparticles were larger than the $30 \mathrm{~nm}$ size.

\subsection{Scanning Electron Micrsocopy}

Figure $4 \mathrm{a}$ represents a typical overview of the sample at very low magnification (X 7500). Analysis of figure reveals the presence of various size particles. Figure $4 \mathrm{~b}$ is an enlarged view of synthesized AgNPs (X 15000 magnification). This image reveals that sample

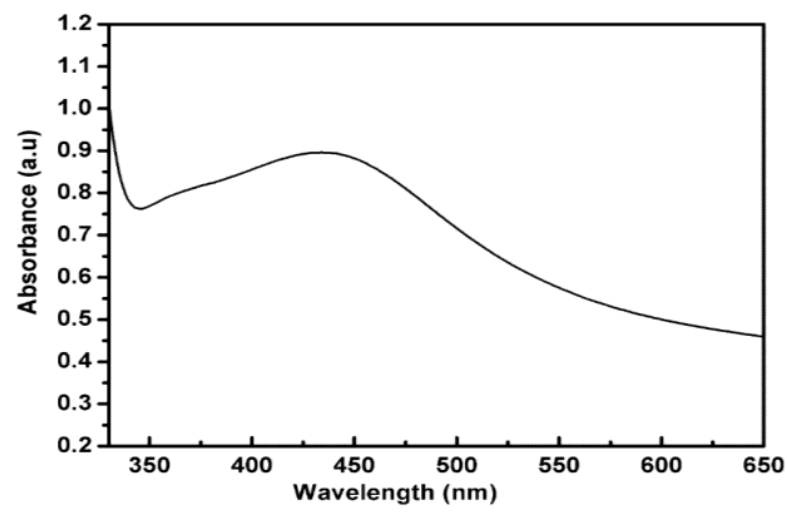

Figure $2 \mathrm{UV}$-vis spectrum of the synthesized Ag nanoparticles using balsam plant extract (Experimental conditions: Conc. of AgNO3 $(1 \mathrm{mM})$, spectrum obtained after $48 \mathrm{~h})$

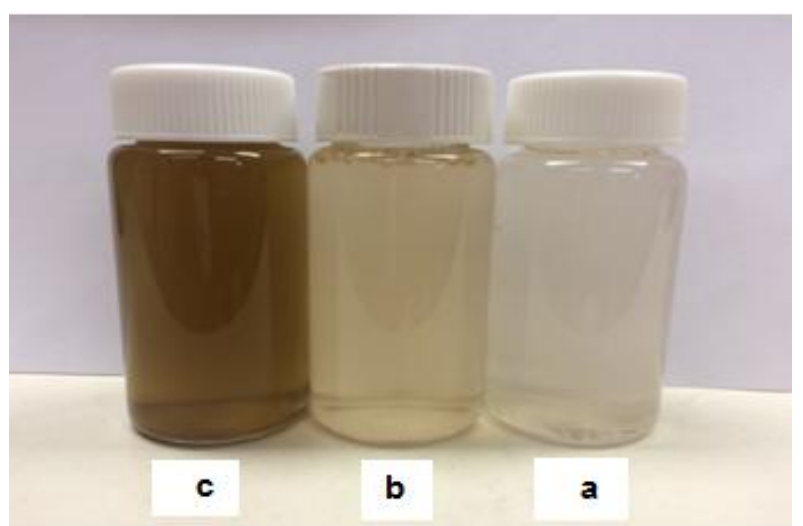

Figure 3 Digital images of balsam plant extract (a) and the synthesized silver nanoparticles $(b, c)$

contained few nanometers sized particles. However, most of the particles were of smaller dimensions. Figure $4 \mathrm{c}$ also shows enlarge view of high magnification (X 15000 magnification), this revealed the presence of some viburnum leaf like structures in the sample at different locations. Final figure (Figure 4d) shows the FESEM image at highest magnification (X 60000), analysis of image (Figure 4d) showed the presence of $\sim 70-115 \mathrm{~nm}$ size AgNPs. These observations are in agreement with the UV-vis spectrum datum, which indicated that the particles were of larger dimensions than $35 \mathrm{~nm}$. These finding corroborate the results obtained by Chauhan et al. (2013) who reported the size of biologically synthesized $\mathrm{Ag}$ nanoparticles in the range of 20-70 nm.

\subsection{Elemental Analysis}

The elemental analysis data of the Ag nanoparticles have been represented in Figure 5. Further, EDX spectrum of these data have been shown in Figure 5a, there are four peaks corresponding to the 

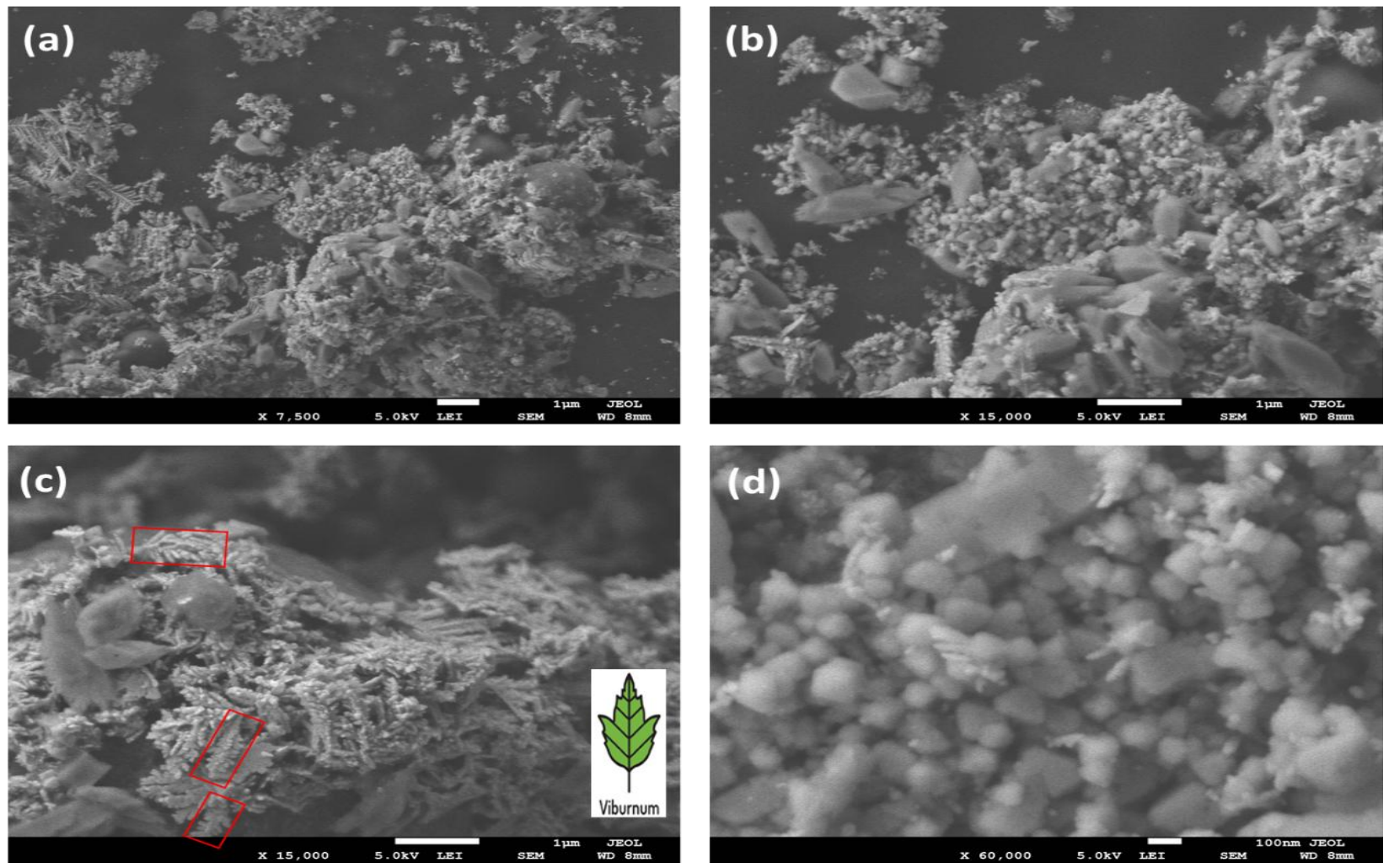

Figure 4 FESEM analysis of the Ag nanoparticles: (a)FESEM image(s) for the surface morphology of the Ag nanoparticles at X 7500,

(b) X15000, (c) X15000 at different location and (d) high magnification of X 60000 .

silver, zinc, carbon and oxygen. Obviously, the $\mathrm{Ag}$ signals were due to the Ag nanoparticles in the sample. The other elements in the sample might be due to the plant source. The total elemental composition of the other elements like carbon, oxygen and zinc in the form of element weight (\%) was 5.17, 3.70 and 5.21 (total $14.07 \%$ ) and atomic 27.99, 15.03 and 5.18 (total 48.2\%), respectively as shown in Figure $5 \mathrm{~b}$. It was found that the most of the samples was composed of the $\mathrm{Ag}$ nanoparticles, as its weight percentage was highest $(85.93 \%)$. Indeed, these results revealed strong signal in the silver region and confirmed the formation of AgNps.

\subsection{Functional Groups analysis}

The FTIR analysis of Ag Nps is shown in Figure 6. Since, the AgNPs were prepared using balsam plant aqueous extract; the organic compounds might be present because of the composition of balsam plant extract. This indicates that the plant extract has played dual role in synthesizing the AgNPs. First, it played a vital role in reducing $\mathrm{Ag}^{1+}$ ions and secondly it worked as capping agent for the synthesized AgNPs. A band of $3789 \mathrm{~cm}^{-1}$ is (a)

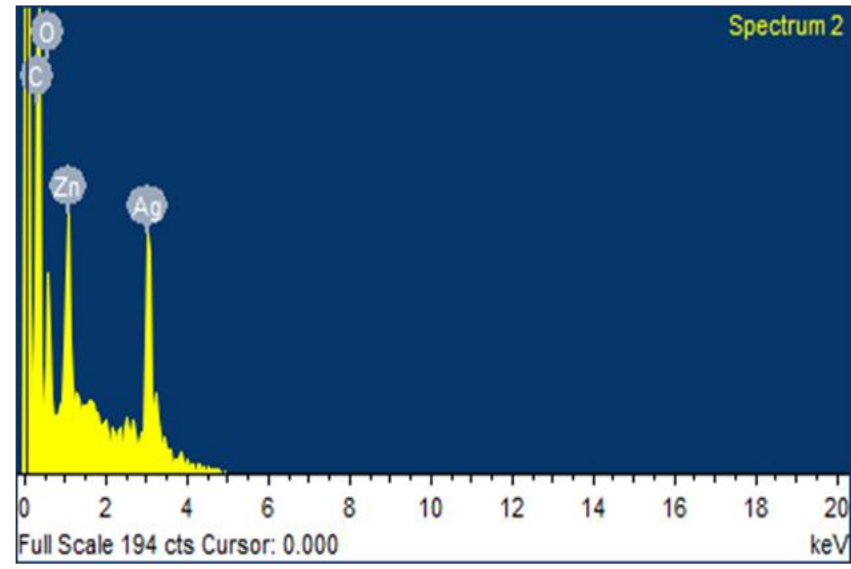

(b)

\begin{tabular}{|l|l|l|}
\hline Element & Weight\% & Atomic\% \\
\hline C K & 5.17 & 27.99 \\
\hline $\mathrm{OK}$ & 3.70 & 15.03 \\
\hline $\mathrm{Zn} \mathrm{L}$ & 5.21 & 5.18 \\
\hline $\mathrm{AgL}$ & 85.93 & 51.80 \\
\hline & & \\
\hline Totals & 100.00 & \\
\hline
\end{tabular}

Figure 5 EDX spectrum (a) and composition of the sample (b) 


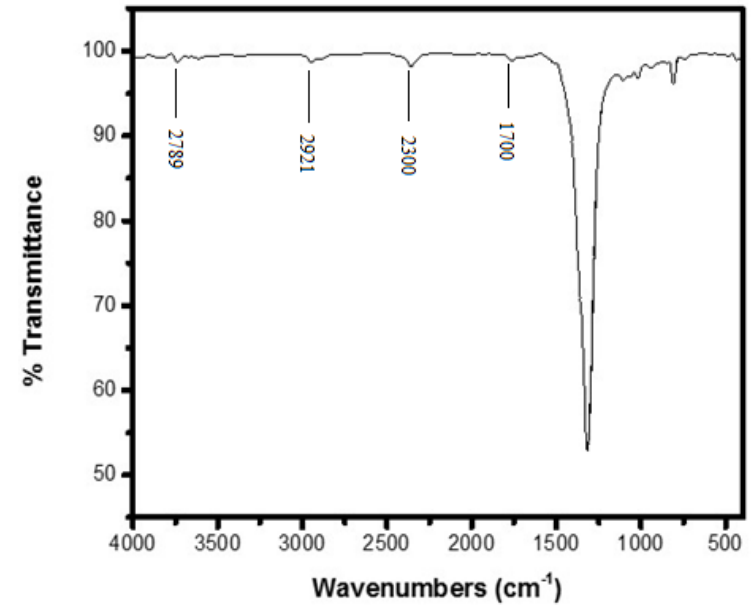

Figure 6 FTIR spectra analysis of AgNps.

due to the $\mathrm{O}-\mathrm{H}$ stretching between oxygen and hydrogen that is attributed to water molecule. Since the sample was dried prior to the FTIR analysis, this peak intensity was lower. However, slight moisture might have resulted in the appearance of this peak. The peak at $2921 \mathrm{~cm}^{-1}$ indicates $\mathrm{C}-\mathrm{H}$ and peak at $2300 \mathrm{~cm}^{-1}$ can be assigned to alkynes group. The band at $1700 \mathrm{~cm}^{-1}$ corresponds to $\mathrm{C}=\mathrm{O}$. The peaks observed during our study corresponds to terpenoids and flavonoid that are normally present on plant material (Banerjee et al., 2014).Results of present study are in agreement with the findings of previous researchers (Banerjee et al., 2014; Pourmortazavi et al., 2015). Results of FT-IR could be concluded that plant contains some bioactive compounds that help in both coating/capping on the nanoparticles.

\section{Conclusion}

In this study, synthesis of AgNps using balsam extract was found efficient and eco-friendly. The characterization of the synthesized AgNps was assessed by several instrumental techniques and it reveals the successful formation of AgNps. Further, antibacterial ability of the synthesized $\mathrm{AgNps}$ was proven against E. coli O157:H7 and multi-drug-resistant Staphylococcus aureus (MRSA). Use of C. gileadensis medicinal plant extract for synthesis of AgNps, is a safer and economic. It can be used as potent broadb and antibacterial agents for biomedical applications.

\section{Significance Statement}

This study elaborated the antibacterial properties of silver nanoparticles against infectious bacteria. It may be beneficial for researcher in order to investigate the mechanism of silver nanoparticle bactericidal activity.

\section{Acknowledgements}

The author would like to thanks Dr.Yasir Anwar from biology department and Mr.M. Aldhahri, technical staff of the biochemistry department for their kindness.

\section{Disclosure of conflicting interests}

The authors declare that there is no conflict of interest to disclose.

\section{Reference}

Abdul-Ghani, AS, Amin R (1997) Effect of aqueous extract of Commiphoraopo balsamum on blood pressure and heart rate in rats. Journal of Ethnopharmacololgy 57:219-222.

Adebayo HA, Song FH, Liu XT, Dai QH, Huang P, Zhang JY, Zhang LX (2014) Citrullus Ianatus Extract Reverses Oxidative and Haematological Dysfuntion in Carbon Tetrachloride Induced Liver Damaged Rats. International Journal of Pharmacology 10:218-224.

Ahmed MS, Kamal T, Khan SA, Anwar Y, Saeed MT, Asiri AM, Khan SB (2016a) Assessment of Anti-bacterial Ni-Al/chitosan Composite Spheres for Adsorption Assisted Photo-Degradation of Organic Pollutants. Current Nanoscience 12:569-575.

Ahmed S, Ahmad M, Swami BL, Ikram S (2016b) A review on plants extract mediated synthesis of silver nanoparticles for antimicrobial applications: A green expertise. Journal of Advance Research 7:17-28.

Ali F, Khan SB, Kamal T, Alamry KA,Asiri AM, Sobahi TRA (2017a) Chitosan coated cotton cloth supported zero-valent nanoparticles: Simple but economically viable, efficient and easily retrievable catalysts. Scientific Report 7:16957.

Ali F, Khan SB, Kamal T, Anwar Y, Alamry KA, Asiri AM (2017b) Bactericidal and catalytic performance of green nanocomposite based-on chitosan/carbon black fiber supported monometallic and bimetallic nanoparticles. Chemosphere 188:588-598.

Ali N, Ismail M, Khan A, Khan H, Haider S, Kamal T (2018a) Spectrophotometric methods for the determination of urea in real samples using silver nanoparticles by standard addition and 2nd order derivative methods. Spectrochimica Acta Part - A Molecular and Biomolecular Spectroscopy 189:110-115.

Ali, F, Khan SB, Kamal T, Alamry KA, Bakhsh EM, Asiri AM, Sobahi TRA (2018b) Synthesis and characterization of metal nanoparticles templated chitosan-SiO2 catalyst for the reduction of nitrophenols and dyes. Carbohydrate Polymers 192:217-230. 
Al-sieni AII (2013) The Antibacterial Activity of Traditionally Used SalvadoraPersica L. (Miswak) and CommiphoraGileadensis (Palsam) in Saudi Arabia. African Journal of Traditional, Complementary Alternative Medicines 11:23-27.

Amiel E, Ofir R, Dudai N, Soloway E, Rabinsky T, Rachmilevitch S (2012) $\beta$-Caryophyllene, a Compound Isolated from the Biblical Balm of Gilead (Commiphora gileadensis), Is a Selective Apoptosis Inducer for Tumor Cell Lines. Available at https://www.hindawi.com/journals/ecam/2012/872394/abs/.

Banerjee P, Satapathy M, Mukhopahayay, Das P (2014) Leaf extract mediated green synthesis of silver nanoparticles from widely available Indian plants: synthesis, characterization, antimicrobial property and toxicity analysis. Bioresources and Bioprocessing 1:3.

Barros CHN, Fulaz S, Stanisic D, Tasic L (2018) Biogenic Nanosilver against Multidrug-Resistant Bacteria (MDRB). Antibiotics 7:69.

Bello BA, Khan SA, Khan JA, Syed FQ, Anwar Y, Khan SB (2017a) Antiproliferation and antibacterial effect of biosynthesized AgNps from leaves extract of Guierasene galensis and its catalytic reduction on some persistent organic pollutants. Journal of Photochemistry and Photobiology B 175:99-108.

Bello BA, Khan SA, Khan JA, Syed FQ, Mirza MB, Shah L, Khan SB (2017b) Anticancer, antibacterial and pollutant degradation potential of silver nanoparticles from Hyphaenethebaica. Biochemical and Biophysical Research Communications 490:889-894.

Chauhan R, Kumar A, Abraham J (2013) A biological approach to the synthesis of silver nanoparticles with Streptomyces sp JAR1 and its antimicrobial activity. Scientia Pharmaceutica 81:607-624.

Haider QR, Azhar A, Frial A (2018)Antibacterial activity of silver nanoparticles extracted from Proteus mirabilis and healing the wound in rabbit. Biochemical and Cellular Archives 18: 97-104.

Iluz, D, Hoffman M, Gilboa-Garber N, Amar Z (2010) Medicinal properties of Commiphoragileadensis. African Journal of Pharmacy and Pharmacology 4:516-520.

Kamal T, Anwar Y, Khan SB, Chani MTS, Asiri AM (2016) Dye adsorption and bactericidal properties of $\mathrm{TiO} /$ chitosan coating layer. Carbohydrate Polymers 148:153-160.

Kamal T, Khan SB, Haider S, Alghamdi YG, Asiri AM (2017) Thin layer chitosan-coated cellulose filter paper as substrate for immobilization of catalytic cobalt nanoparticles. International Journal of Biological Macromolecules 104:56-62.

Khan S, Ul-Islam M, Khattak WA, Ullah W, Park JK (2015) Bacterial cellulose-titanium dioxide nanocomposites: nanostructural characteristics, antibacterial mechanism, and biocompatibility. Cellulose 22:565-579.

Kuppusamy P, Yusoff MM, Maniam GP, Govindan N (2016) Biosynthesis of metallic nanoparticles using plant derivatives and their new avenues in pharmacological applications-An updated report. Saudi Pharmaceutical Journal 24:473-484.

Miller AG, Morris M, Stuart-Smith S (1988) Plants of Dhofar: the southern region of Oman: traditional, economic and medicinal uses. Office of the Advisor for Conservation of the Environment, Diwan of Royal Court.

Mittal AK, Chisti Y, Banerjee UC (2013) Synthesis of metallic nanoparticles using plant extracts. Biotechnology Advances 31:346-356.

Pourmortazavi SM, Taghdiri M, Makari V, Rahimi-Nasrabadi M (2015) Procedure optimization for green synthesis of silver nanoparticles by aqueous extract of Eucalyptus oleosa. Spectrochimica Acta Part - A Molecular and Biomolecular Spectroscopy 136:1249-1254.

Shaheen M, Khan RA, Ahmed M, Mushtaq N, Khan N (2017) Antidiabetic Efficacy of Methanolic Crude Extract of Quercusdilatata Fruit: A Randomized Control Trial. International Journal of Pharmacology 13:501-506.

Singh P, Garg A, Pandit S, Mokkapati VRSS, Mijakovic I (2018) Antimicrobial Effects of Biogenic Nanoparticles. Nanomaterials $8: 1009$.

Sondi I, Salopek-Sondi B (2004) Silver nanoparticles as antimicrobial agent: a case study on E. coli as a model for Gram-negative bacteria. Journal of Colloid Interface Science 275:177-182.

Wajid Ullah M, Ul-Islam M, Khan S, Kim Y, Hyun Jang J, Kon Park J (2016) In situ synthesis of a bio-cellulose/titanium dioxide nanocomposite by using a cell-free system. RSC Advances 6:22424-22435.

Wineman E, Douglas I, Wineman V, Sharova K, Jaspars M, Meshner S, Bentwich Z, Cohen G, Shtevi A (2015) Commiphoragileadensis sap extract induces cell cycle-dependent death in immortalized keratinocytes and human dermoid carcinoma cells. Journal of Herbal Medicine 5:199-206. 